\title{
Análise das Despesas Orçamentárias do Estado do Piauí de 2013 a 2016: Os Gastos com Despesas Correntes e de Capital
}

\section{Analysis of Budgetary Expenditure of the State of Piauí from 2013 to 2016: Expenditure on Current and Capital Expenditure}

Gilberto Soares da Silva ${ }^{1}$ Ana Lúcia de Medeiros²

\section{RESUMO}

As despesas públicas são os gastos realizados pelo setor público para funcionamento e manutenção das atividades ou políticas desenvolvidas para a sociedade. Para isso, temos que o orçamento público é o mecanismo governamental utilizado para planejamento, sendo este, o instrumento legal onde se encontram fixadas as despesas públicas para determinado exercício financeiro. Dessa maneira, este trabalho analisa as despesas orçamentárias do estado do Piauí no período de 2013 a 2016, considerando as despesas pagas neste interstício. $O$ presente estudo está fundamentado por meio de uma análise documental, com base em dados extraídos do Sistema de Informações Contábeis e Fiscais do Setor Público Brasileiro (Siconfi). Mediante a tabulação e análise dos dados coletados, percebeu-se grande destinação de gastos com despesas correntes se equiparadas às de capital, principalmente, gastos com pessoal e encargos sociais, seguidos de aquisição de bens de consumo e gastos com auxílios e contribuições. Assim, conclui-se que os fatores institucionais e a legislação vigente contribuem na forma como estes gastos são efetuados no estado do Piauí.

Palavras-Chave: Orçamento público. Despesas orçamentárias. Gastos públicos.

\section{ABSTRACT}

Public expenditures are expenditures by the public sector for the operation and maintenance of activities or policies developed for society. For this, we have that the public budget is the governmental mechanism used for planning, being this, the legal instrument where the public expenses for a given financial year are fixed. Thus, this paper analyzes the budget expenditures of the state of Piauí in the period from 2013 to 2016, considering the expenses paid in this interstice. The present study is based on a documentary analysis, based on data extracted from the Accounting and Tax Information System of the Brazilian Public Sector (Siconfi). By tabulating and analyzing the data collected, it was possible to allocate expenditures with current expenditures when they were equivalent to capital expenditures, mainly personnel expenses and social charges, followed by the acquisition of consumer goods and expenses with aids and contributions. Thus, it is concluded that institutional factors and current legislation contribute to the way these expenditures are carried out in the state of Piauí.
Bacharel em Administração pela Universidade Federal do Piauí - UFPI (2012); Especialista em Gestão de Recursos Humanos e Meio Ambiente, pela Universidade Cândido Mendes, Rio de Janeiro (2015); Mestrando pelo Programa de Mestrado Profissional em Gestão de políticas Públicas; Atualmente Administrador na Universidade Federal do Tocantins

E-mail: gilbertosoares@uft.edu.br

${ }^{2}$ Possui graduação em Ciências Econômicas pela Universidade Federal da Paraíba (1997), mestrado em Economia pela Universidade Federal da Paraiba (2001) e doutorado em Administração de Empresas pela Universidade Presbiteriana Mackenzie (2013). Realizou estágio doutoral no ISCTE/IUL em Lisboa - PT (2012). Atualmente é diretora do Campus Universitário de Palmas e professora adjunto III - do curso de ciências econômicas, do mestrado profissional em gestão de políticas públicas e do mestrado profissional em Administração Pública da UFT.

Keywords: Public budget. Budgetary expenditures. Public spending. 


\section{INTRODUÇÁO}

O contexto econômico sob a ótica das finanças públicas teve em seu processo de consolidação diferentes abordagens e ideias. De acordo com as Teorias Clássicas e Neoclássicas, mais precisamente no caso da visão de Smith, para que o sistema econômico fosse equilibrado seria desnecessária a intervenção estatal, exceto em casos estritamente imprescindíveis (SANTOS, 2001).

Para o teórico Keynes em oposição às visões de seus predecessores - Smith, Say e Ricardo, sustentava que a presença do estado é fundamental na regulação das políticas econômicas, desempenhando funções primordiais para a estabilização da economia, distribuição de renda e alocação de recursos (REZENDE, 2001).

As finanças públicas ou a política fiscal no caso do Brasil está configurada numa interrelação político-econômica entre os governantes e os governados. Sob a ótica do pacto federativo, essa relação está comprometida por uma série de nuances entre os entes federativos, no desenho e implementação política (DAIN, 2001).

Para se chegar a uma política fiscal desejável, ou melhor, equilibrada, o Brasil planeja sua política orçamentária com base em três instrumentos constitutivos, nas três esferas governamentais, são eles: Plano Plurianual (PPA), onde estão fixadas as diretrizes, objetivos e metas da Administração Pública Federal para as despesas de capital e outras que delas possam decorrer e programas de longa duração, a Lei de Diretrizes orçamentárias (LDO) que detalha e quantifica para cada exercício financeiro, as metas, as prioridades e as metas fiscais da administração que serão usadas no desenho do orçamento anual, e a Lei Orçamentária anual (LOA) define e detalha as receitas e os gastos anuais, estabelecendo fortes vínculos com os demais instrumentos orçamentários (ROCHA, 2008; SANCHES, 2017).

Nesse sentido, após a legalização da reforma tributária promovida via Constituição Federal de 1988 (CF de 88), com a descentralização na formulação e implementação de políticas públicas, os estados brasileiros passaram a vivenciar uma crise fiscal severa, em virtude da expansão das despesas orçamentárias, ao passo que as receitas não acompanharam tal crescimento, mesmo quando a arrecadação tributária apresentou melhores desempenhos (BRASIL, 1988).

Para Holanda (1997) cabe aos governos dos estados brasileiros caminharem de encontro à modernização administrativa e melhoria do desempenho fiscal. Pois, analisa-se 
grande crescimento nas despesas com gastos de pessoal, com crescimentos progressivos a cada ano, mostrando ser insustentável se analisadas pela ótica do equilíbrio fiscal.

Diante do exposto, buscou-se avaliar o cenário das finanças públicas do Piauí no interstício de 2013 a 2016 no que se refere aos gastos públicos, visando absorver detalhes contidos na contabilização dos dados. Para isso, utilizaram-se bancos de dados do Siconfi, distribuindo os dados em despesas correntes e de capital, e posteriormente por grupos, para fazer comparações.

A proposta deste artigo está estruturada em três partes principais, com exceção desta introdução. A primeira busca descrever os conceitos das despesas orçamentárias com base no Manual de Contabilidade Aplicada ao Setor Público de acordo com suas classificações. Em seguida, apresenta-se a estrutura metodológica da análise e tabulação dos dados. Por fim, apresentam-se os principais resultados da pesquisa seguidas das considerações finais.

\section{CLASSIFICAÇÄO DAS DESPESES PUBLICAS}

Antes de compreendermos acerca das despesas públicas, abordaremos alguns conceitos prévios e necessários para chegarmos às características dos gastos públicos. A política fiscal no Brasil compreende as receitas e as despesas públicas. Neste sentido, para que a política fiscal seja saudável, torna-se imprescindível o planejamento enquanto estrutura orçamentária.

Tendo como fundamento o Manual de Contabilidade Aplicada ao Setor Público, temos que o orçamento é o mecanismo de planejamento de entidades, sejam públicas ou privadas, que descreve as entradas e saídas de recursos em determinado período.

No caso do setor público, independente da esfera federativa (União, Distrito Federal, estados e munícipios) ou mesmo, entre os poderes, Executivo, Legislativo e Judiciário, esse planejamento tem função primordial, por ser o instrumento legal onde se encontram fixadas as despesas públicas para o exercício financeiro.

As despesas públicas são os gastos realizados pelo setor público para funcionamento e manutenção das atividades ou políticas desenvolvidas para a sociedade. Assim, podemos classificar os gastos públicos em três vertentes que consideram: a finalidade do gasto, a natureza do dispêndio, e quanto ao agente encarregado da execução.

Acerca do agente encarregado da execução, de acordo com a Lei 4.320/1964, temos a classificação institucional, que reflete a estrutura funcional dos créditos orçamentários e reflete sob dois níveis: órgão orçamentário e unidade orçamentária (BRASIL, 1964). 
Quanto à finalidade, as subdivisões estão elencadas em funções, programas e subprogramas, de acordo com o nível agregado na adoção, cuja descrição se encontra na Portaria n 42/1999, do então Ministério do Orçamento e Gestão. Nesse sentido, função é o maior nível de agregação das diversas áreas da despesa, podendo ainda possuir várias subfunções. Os programas e subprogramas são métodos governamentais de efetivar políticas e ações quanto aos objetivos propostos em atendimento às demandas sociais ou na resolução de problemas (BRASIL, 1999).

A classificação da despesa orçamentaria, quanto à natureza do gasto, se divide em: categoria econômica, grupo de natureza de despesa e elemento da despesa. Como a proposta deste estudo visa elencar as despesas do estado do Piauí e acerca das categorias econômicas e dos grupos da despesa, dedicar-se-á na descrição mais detalhada de suas caracterizações.

Todas essas particularidades, tanto no que tange as receitas e despesas são caracterizadas por códigos numéricos, que no caso das categorias econômicas, temos: 1 - receitas correntes; 2 - receitas de capital; 3 - despesas correntes; e, 4 - despesas de capital.

No caso da despesa em relação à natureza orçamentária, o código final é composto por seis dígitos, sendo o primeiro referente à categoria econômica, onde despesas correntes são os gastos que contribuem de modo direto no custeio ou manutenção dos serviços públicos, e despesas de capital, são as que contribuem diretamente na instauração e obtenção desses bens, sejam ativo imobilizado, intangível/investimento ou registro de desincorporação de um passivo.

Os grupos de natureza da despesa formam o segundo dígito da codificação e estão distribuídos em algarismos de 1 a 6, correspondendo, respectivamente a, pessoal e encargos sociais, juros e encargos da dívida, outras despesas correntes, investimentos, inversões financeiras e amortização da dívida. Vale ressaltar, que os três primeiros grupos estão enquadrados nas despesas correntes, enquanto os últimos em despesas de capital, conforme tabela 01.

Tabela 01. Classificação da despesa do gasto por natureza 


\section{Despesas correntes}

1 Pessoal e encargos sociais - Despesas orçamentárias com pessoal ativo e inativo e pensionistas, relativas a mandatos eletivos, cargos, funções ou empregos, civis, militares e de membros de Poder, com quaisquer espécies remuneratórias, tais como vencimentos e vantagens, fixas e variáveis, subsídios, proventos da aposentadoria, reformas e pensões, inclusive adicionais, gratificações, horas extras e vantagens pessoais de qualquer natureza, bem como encargos sociais e contribuições recolhidas pelo ente às entidades de previdência, conforme Lei complementar 101/2000 em seu Art. 18.

2 Juros e encargos da dívida - Despesas orçamentárias com o pagamento de juros, comissões e outros encargos de operações de crédito internas e externas contratadas, bem como da dívida pública mobiliária.

3 Outras despesas correntes - Despesas orçamentárias com aquisição de material de consumo, pagamento de diárias, contribuições, subvenções, auxílioalimentação, auxílio-transporte, além de outras despesas da categoria econômica "Despesas Correntes" não classificáveis nos demais grupos de natureza de despesa.

\section{Despesas de Capital}

4 Investimentos - Despesas orçamentárias com softwares e com o planejamento e a execução de obras, inclusive com a aquisição de imóveis considerados necessários à realização destas últimas, e com a aquisição de instalações, equipamentos e material permanente.

5 Inversões financeiras - Despesas orçamentárias com a aquisição de imóveis ou bens de capital já em utilização; aquisição de títulos representativos do capital de empresas ou entidades de qualquer espécie, já constituídas, quando a operação não importe aumento do capital; e com a constituição ou aumento do capital de empresas, além de outras despesas classificáveis neste grupo.

6 Amortização da dívida - Despesas orçamentárias com o pagamento e/ou refinanciamento do principal e da atualização monetária ou cambial da dívida pública interna e externa, contratual ou mobiliária.

Os códigos finais da despesa orçamentária se referem à modalidade de aplicação (dois dígitos) que corresponde à indicação se os recursos serão executados diretamente por órgãos ou entidades da mesma esfera governamental ou por outro ente federado e seus institutos, o que possibilita a diminuição de dupla contagem de recursos transferidos ou descentralizados.

Quanto às etapas, a despesa orçamentária passa por duas fases principais, a saber: o planejamento e a execução. De acordo com esta proposta focaremos nesta última por contribuir melhor com análise das fases que compõem esse processo. Portanto, de acordo 
com a Lei no 4.320/1964, a execução é realizada em três estágios, que são: o empenho, a liquidação e o pagamento (BRASIL, 1964).

O empenho conforme o art. 58 da Lei nº 4.320/1964, é o ato emanado de autoridade competente que cria para o Estado obrigação de pagamento pendente ou não de implemento de condição. Consiste na reserva de dotação orçamentária para um fim específico.

A liquidação por sua vez, á ação que valida o direito adquirido mediante o credor, baseado em títulos e documentos que comprovem o respectivo crédito, tendo por finalidade, averiguar a origem e o objeto credor, a importância a pagar e o sujeito a quem deve ser paga a importância, eliminando assim a obrigação.

Por fim, o pagamento incide na cessão do numerário ao credor através de cheque nominativo, ordens de pagamentos ou crédito em conta, somente pode ser efetivado após a liquidação da despesa. A Lei n 4.320/1964, no art. 64, determina ordem de pagamento como o envio registrado por autoridade competente, definindo que a despesa liquidada seja paga.

Para efeitos de análise das despesas do estado do Piauí, a base principal são as despesas pagas, uma vez que as despesas empenhadas ou liquidadas no exercício financeiro e que não foram pagas, passam para o exercício seguinte como restos a pagar $(\mathrm{RP})$, sendo que os restos a pagar se classificam ainda como: RP processados (que passaram pela liquidação da despesa) e RP não processados (que foram apenas empenhados).

Desse modo, faz-se necessário descrever o objeto deste estudo, assim como a trilha metodológica realizada para a tabulação e análise dos dados no sentido de facilitar o entendimento dos dados propostos, conforme descrito nas seções adiante.

\section{METODOLOGIA}

O Estado do Piauí fica localizado no noroeste do Nordeste brasileiro, conta com uma extensão territorial em torno de mais de 251 mil Km², e uma população no ano de 2016 estimada em pouco mais de 3,2 milhões de habitantes. A capital do Estado é Teresina, sendo que no total os municípios piauienses chegam ao número de 224.

O estado está dividido em quatro mesorregiões e 15 microrregiões. Tem um relevo moderado, tendo como principais rios: Parnaíba, Poti, Canindé, Piauí e São Nicolau, todos pertencentes à bacia do Rio Parnaíba. Seu clima é o tropical e semiárido. Tem como 
principais atividades econômicas a indústria, em especial a química, têxtil, de bebidas; também se destaca na agricultura, com grande produção de algodão, arroz, cana-deaçúcar, mandioca, e também pecuária.

Com relação à metodologia do estudo, os procedimentos foram realizados por meio de análise documental e, os dados foram coletados junto à Sicofi, no interstício de 2013 a 2016. A análise dos dados foi separada de duas formas, a primeira observou os gastos inscritos na rubrica das categorias de despesas correntes e de capital, sem levar em consideração os gastos com os grupos de natureza de despesa. A outra maneira de separação dos dados foi por grupo de natureza de despesa, essa por sua vez, não considerou os gastos inscritos nas categorias.

As tabelas de análise consideraram ainda uma separação conforme os estágios da despesa: empenho (DE), liquidação (DL) e pagas (DP). Os valores que apresentam percentuais, em sua maioria consideram o período inicial (2013) e o final (2016), ou mesmo a somatória dos períodos. Quando nos referimos aos gastos totais governamentais, estamos considerando o montante dos gastos por categoria e por grupo. Vale destacar ainda que, boa parte da análise considerou apenas as despesas pagas, por representarem melhor o total do que foi de fato despendido pelo estado no período, salvo os casos em que se analisa as RP processadas e não processadas.

\section{ANALISE E DISCUSSAO DOS RESULTADOS}

Para que possamos analisar as despesas do governo do Piauí referentes as despesas públicas de 2013 a 2015, dividimos a seção em duas partes, a primeira se refere aos gastos inscritos na categoria econômica de modo generalizado, sem considerar os dispêndios dos grupos a elas pertencentes, depois, analisam-se os gastos de acordo com os grupos de natureza da despesa, ao final fazendo um balancete geral das despesas correntes e de capital.

\subsection{Despesas Correntes e de Capital do Estado do Piauí}

Quando buscamos perceber a composição das despesas em relação aos objetivos governamentais, pode-se inferir se o governo aplicou recursos na promoção do crescimento econômico e na redistribuição de Renda. Mas, de acordo com Rezende (2001), essa classificação tem suas restrições, pois algumas receitas que são inscritas no custeio se 
referem a algumas ações importantes para o crescimento econômico e distribuição de renda, em proporção bem maior que outras despesas de investimento ou transferências.

Para efeitos dessa primeira seção de análise levaremos em conta apenas os gastos inscritos nas rubricas, conforme dados e valores da tabela 2 .

Tabela 02. Total de gastos de 2013-2016 com despesas correntes e de capital.

\begin{tabular}{|c|c|c|}
\hline \multicolumn{3}{|c|}{ 3.0.00.00.00.00 - Despesas correntes } \\
\hline Empenhadas & Liquidadas & Pagas \\
\hline $\mathrm{R} \$ 27.158 .407 .222,66$ & $R \$ 26.952 .629 .137,05$ & $\mathrm{R} \$ 25.628 .310 .029,76$ \\
\hline \multicolumn{3}{|c|}{ 4.0.00.00.00.00 - Despesas de Capital } \\
\hline Empenhadas & Liquidadas & Pagas \\
\hline$R \$ 4.957 .559 .500,60$ & $\mathrm{R} \$ 4.718 .399 .311,68$ & $R \$ 4.605 .825 .745,94$ \\
\hline
\end{tabular}

Em análise prévia dos dados do Siconfi, foi ponderado um crescimento relativo das despesas no decorrer desses quatro anos, sendo que em comparação entre o período final e o inicial o aumento nas despesas correntes circunda em torno de $38,2 \%$, enquanto as despesas de capital tiveram um rendimento que não ultrapassou $0,5 \%$. Quando comparamos essas despesas, depreendem-se que com a CF de 88, as despesas vinculadas apresentam forte rigidez em razão dos fatores institucionais, nesse sentido os gastos com investimentos estão sujeitos aos cortes, por sua volatilidade e em virtude das políticas de ajuste fiscal (REZENDE, 2001).

Quando os valores foram somados para mostrar um panorama geral dentro desse período, podemos analisar conforme o gráfico 01 (ver anexo tabelas e gráficos), que de todos os gastos desprendidos com despesas de capital e corrente, a participação das despesas de capital ainda são bastante incipientes. O gráfico apresenta o total das despesas empenhadas (DE), liquidadas (DL) e pagas (DP).

Gráfico 01. Total das despesas correntes e de Capital de 2013 a 2016.

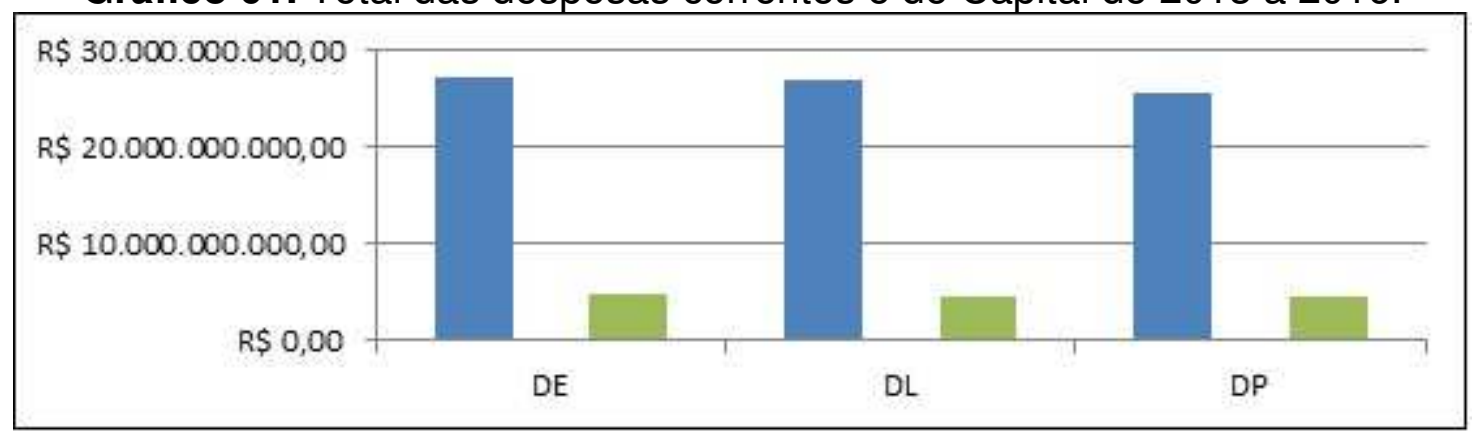


Esse resultado mostra que o gasto total com despesas correntes é muito superior aos gastos com investimento e distribuição de renda. Quando a etapa das despesas pagas é analisada, percebem-se que a participação das despesas correntes atinge o percentual de $85 \%$ do total dos gastos, já as despesas de capital atinge apenas $15 \%$ dos gastos. Uma análise mais detalhada nos permite observar que, as despesas correntes apresentaram um crescimento relativo na participação dos gastos a cada ano. As despesas de capital, ao contrário, em 2015 teve uma queda de quase 50\% em relação a 2013, em números relativos, caindo de cerca de 1,3 bilhões para 773 milhões.

Com relação aos Restos a Pagar (RP) processados e não processados, percebemos que o montante total em relação aos quatro anos é um valor significativo, sendo que para as despesas correntes os valores chegam a 1,3 e 1,5 bilhões, respectivamente, e de $112 \mathrm{e}$ 351 milhões, para as despesas de capital. Os percentuais desses valores sobre o total de despesas pagas é de 4,7\% para os RP processados e de 6,2\% para não processados.

Ainda nesse contexto, é comum que a contabilidade seja maquiada para disfarçar um possível superávit primário, onde as despesas empenhadas e liquidadas são geradas no final do exercício para que o pagamento ocorra em anos posteriores. Detém-se com isso que o governo do Piauí apresenta uma despesa de restos a pagar com valor superior a $10 \%$ do total das despesas pagas, carecendo de estudos mais aprofundados por não ser objetivo dessa análise.

No geral, a média dos gastos para o período analisado foi de pouco mais de 6,5 milhões com despesas correntes e de 1,1 milhões com despesas de capital, sem inserir nesses números os valores pagos aos grupos de natureza de despesa, que serão detalhados na seção a seguir.

\subsection{Grupos de Natureza da Despesa}

Os seis grupos de natureza da despesa possuem um dispêndio de gastos com valores percentuais equiparados aos estudados na seção anterior. $O$ total de gastos com os grupos: pessoal e encargos sociais, juros e encargos da dívida, e outras despesas correntes foi de $84,5 \%$, já o total com investimentos, inversões financeiras, e amortização da dívida chegou a $15,5 \%$.

Levando em consideração que algumas despesas orçamentárias estão vinculadas, em atendimento a CF de 88, como por exemplo, gastos com Educação, Saúde, transferências intergovernamentais, percebe-se que a participação dos gastos com as 
despesas de capital tem uma representação significativa, embora estejam mais sujeitas aos cortes governo em épocas de crise orçamentária ou de ajustes fiscais.

Por outro lado, ao analisar os percentuais de participação de cada um dos grupos em relação ao valor total de gastos com despesas correntes e de capital, temos a representação no gráfico 02 (ver anexo tabelas e gráficos). Ratificando o que mencionado anteriormente sobre a participação significativa do grupo de natureza de despesas associados às despesas correntes em relação aos de capital.

Gráfico 02. Percentual dos grupos de natureza de despesa sobre o total dos gastos públicos do Piauí.

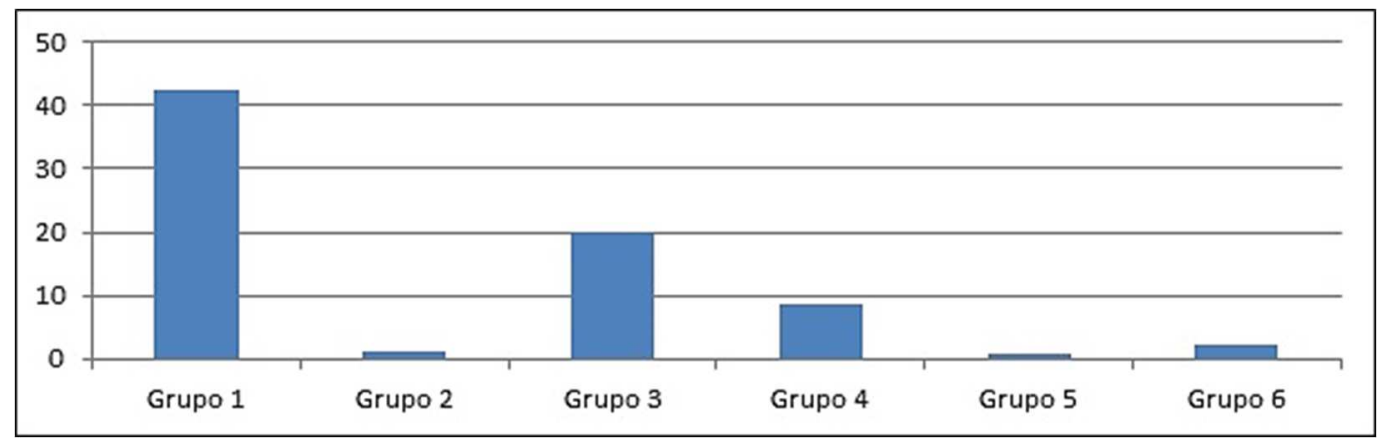

Em exame ao gráfico acima, tem-se que os gastos com o grupo pessoal e encargos sociais representam $42 \%$ dos gastos totais, sendo que conforme Lei complementar $101 / 2000$, os gastos com pessoal não deverá ultrapassar o total de 60\% das receitas correntes líquidas, no caso do governo do Piauí esse gasto representa $32,4 \%$. Nos gastos com juros e encargos da dívida, o governo piauiense gastou cerca de 1,2\% sobre os gastos totais, que embora represente um quantitativo baixo, em termos gerais esse valor chega a mais de 1,5 milhões no período estudado.

Para fechar a categoria temos o grupo de outras despesas correntes, que chega ao total de $19,8 \%$, ou seja, quase metade do valor gasto com pessoal e encargos sociais. $O$ grupo dos gastos com investimentos representa pouco mais de 8,5\% dos gastos totais, enquanto as inversões financeiras representam 0,9\%, e os gastos com a amortização da dívida 2,2\%.

Em termos gerais, ao observarmos os detalhes dos gastos do estado do Piauí, percebe-se que nos grupos de natureza de despesa, os gastos com pessoal e encargos sociais (grupo 1) apresentaram crescimento em todos os anos de 2013 a 2016, sendo que ao comparar os gastos realizados no início e no final do interstício, os gastos representam um total de $74 \%$. Importante reforçar que os gastos desse grupo se referem ao pessoal 
ativo, inativos e pensionistas, referentes a encargos eletivos, cargos, funções ou empregos, civis, militares e de membros de Poder.

Mesmo com esse percentual de gastos tendo aumentado, verificamos que o Estado Piauiense não ultrapassou o limite de gastos com pessoal permitido aos estados da federação. Analisando os dados foi possível observar que praticamente durante todo o período, os maiores gastos do grupo 1 de natureza de despesa foram com pessoal e encargos, aplicações diretas e vencimentos e vantagens fixas com pessoal civil. O total desses três gastos no ano de 2016 chegam a representar $75 \%$ dos gastos do grupo neste exercício financeiro.

No grupo 2, que são os gastos com juros e encargos da dívida - as operações de crédito contratadas interna ou externamente, ou também com dívida pública mobiliária apresentaram um crescimento no interstício dos quatro anos analisados, apresentando um crescimento de $42 \%$ ao final do período em relação ao inicial. Como discutido anteriormente a participação desses gastos com relação ao total de despesas do Piauí apresenta um valor ínfimo, embora tenha representação superior aos gastos com alguns grupos de despesas de capital, como é o caso das inversões financeiras.

Os gastos com outras despesas correntes, grupo 3, diferente desses grupos dessa categoria teve uma queda de 64\% na participação dos gastos do grupo, de 2013 para 2014. Já nos outros dois anos do período analisado o grupo apresentou crescimento, embora cumpra destacar que ao final do período, ou seja, em 2016 o valor total dos gastos com outras despesas correntes, ainda estava com um valor 7\% menor que o ano de 2013.

Neste sentido, podemos aferir que os gastos com materiais para consumo, pagamento de diárias, contribuições, subvenções, auxílio-alimentação, auxílio-transporte foram despesas que sofreram cortes, principalmente no ano de 2014. Destaca-se ainda que os gastos mais representativos no decorrer do período foram com as rubricas de outras despesas correntes e aplicações diretas, somando juntas no ano de 2016 um percentual de $65 \%$, mais da metade dos gastos totais do grupo.

Ao analisarmos os grupos da categoria despesas de capital, o grupo dos investimentos (grupo 4) tem a maior participação sobre as despesas totais do período, cerca de 8,5\%, embora do ano de 2013 a 2016 o grupo venha apresentando oscilações entre um ano e outro, e quando comparado o período inicial com o final, percebemos uma queda de $5 \%$ dos gastos. Quando esse grupo sofre queda ou aumento, inferimos que o governo estará investindo ou não, em obras, softwares, imóveis necessários à realização de projetos [obras], instalações ou material permanente. Os maiores dispêndios desse 
grupo são com investimentos e aplicações diretas, seguidos das obras e instalações, que juntos somam quase $90 \%$ dos gastos referentes a esse grupo de natureza de despesa.

As inversões financeiras ou grupo 5 , apesar de ter baixa participação sobre o valor total das despesas, menos de 1\%, apresentou uma queda de $81 \%$ de 2013 para 2014, reestabelecendo os valores e crescendo nos outros dois anos. $O$ ano de 2016 fechou com um valor de $118 \%$ superior ao ano de 2013 , mostrando que a tendência dos gastos com aquisição de imóveis e/ou bens de capital, aquisição de títulos empresariais tiveram um grande aumento nos anos finais do período analisado.

Os gastos do grupo 6, ou as despesas com a amortização da dívida, que são os gastos com pagamentos e/ou refinanciamento referentes a atualização monetária ou cambial da dívida pública, tanto interna quanto externa apresentaram crescimento no decorrer do período, sendo que em 2016 o aumento foi de 11\% em relação a 2013. Disso, podemos concluir que a dívida vem sendo renegociada, uma vez que as limitações dos estados em arcar com os gastos vêm adquirindo maiores dificuldades.

Outra observação que pode ser feita é com relação aos gastos por função, nos ajuda inferir os gastos com Educação, Saúde, Administração geral, as despesas intraorçamentárias, entre outras, conforme mostra o gráfico 03 (ver anexo tabelas e gráficos). Para levantamento das informações foram comparados os gastos totais do ano de 2016, e o total de gastos por função do mesmo ano, no gráfico foram disponibilizados apenas os gastos das funções com participação superior a $1 \%$ dos gastos totais.

Gráfico 03. Percentual de gastos por função em relação aos gastos totais de 2016

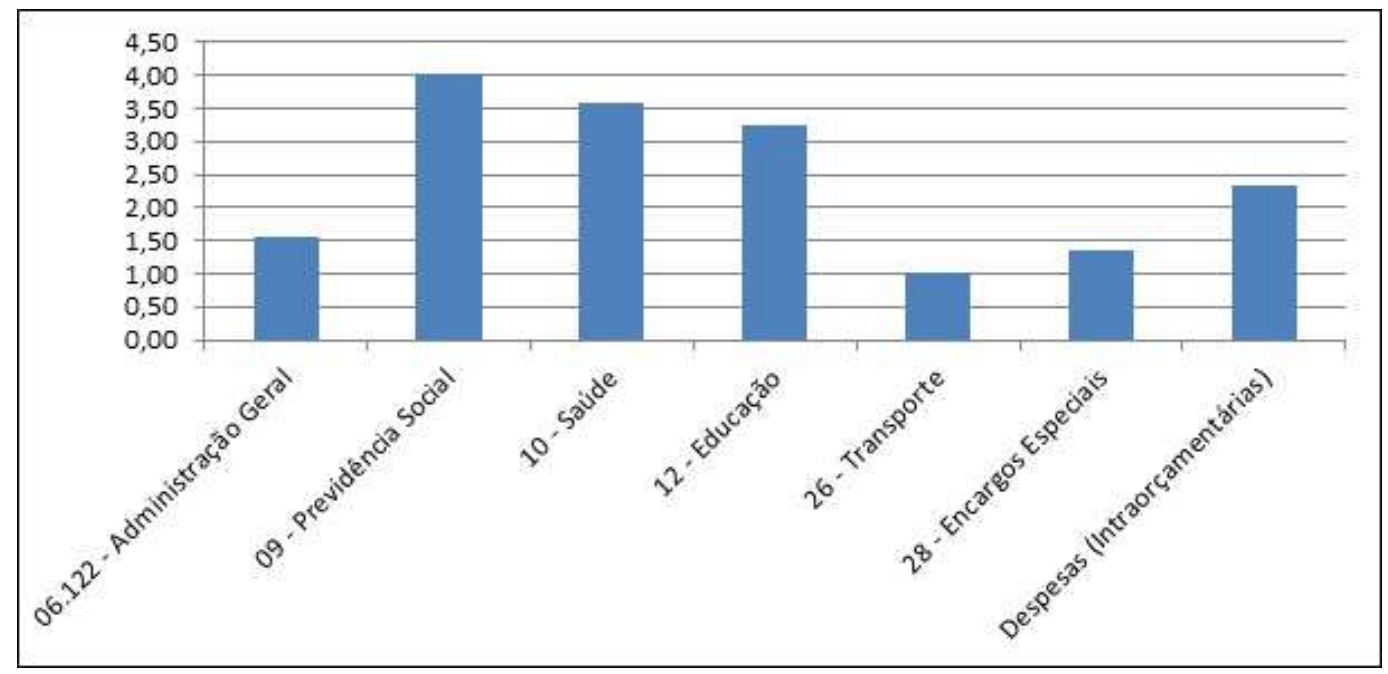

Percebe-se que os maiores gastos, respectivamente, são dispêndios realizados com: previdência social, saúde, educação, despesas - intraorçamentárias, administração geral, 
encargos especiais e transporte. Esses números refletem o motivo pelo qual os gastos com despesas correntes são bem superiores aos gastos com investimentos. Em outras palavras, podemos observar que gastos associados à manutenção de serviços de Saúde e Educação, possui correlação direta com gastos referentes ao crescimento econômico e distribuição de renda.

A CF de 88 contribui em muito para o aumento de gastos em algumas funções, como podemos citar o caso, da Previdência Social, por meio da concessão de benefícios previdenciários, o piso salarial mínimo para esses beneficiários, renda mensal vitalícia para idosos e pessoas portadoras de deficiências físicas. Outra observação se deve às mudanças da estrutura etária brasileira, onde aumentou o número de pessoas idosas e maior expectativa de vida.

Os gastos com pessoal por sua vez, possuem também solidez na participação dos gastos, uma vez que a mesma Constituição admite quadro de pessoal com estabilidade, e a baixa intervenção do Estado com políticas de demissões ou mesmo o peso que gera a inatividade, provocando um aumento significativo com esses gastos, independente da área. Podemos inclusive considerar também que mesmo nos gastos que seriam dispendidos para despesas de capital, como obras, transportes, urbanismo, conta-se com mão de obra especializada e parte dos gastos serão destinados aos gastos com pessoal.

Em suma, os gastos com pessoal e previdenciários são fortemente assegurados por fatores institucionais, isso resulta em menores gastos com despesas de capital, primeiro por estarem mais propensas aos cortes, segundo que após as retiradas das despesas obrigatórias e vinculadas, os governos são obrigados a investirem com o restante dessas receitas, e aqui entram outras nuances como os acordos políticos, superestimação de receita, maquiagem contábil, fragilidade institucional para o accountability que não são objetivos deste paper.

Antes das considerações finais apresenta-se ainda uma reflexão acerca do total das receitas correntes liquida e os totais de despesas do período, mostrando que o estado do Piauí apresentou entre os anos de 2013 a 2016, um superávit primário de mais de 38,6 bilhões, que merece outras propostas de estudo para detalhar as particularidades desse resultado. 
Objetivou-se com este estudo fazer um balanço dos gastos do governo do Piauí com as despesas correntes e de capital, entre os anos de 2013 e 2016. Os estados brasileiros no geral passam por crises fiscais, onde a quantidade de receitas não supera as despesas totais, geralmente em função de gastos obrigatórios, algumas dificuldades de tributação, ou mesmo com o aumento de gastos com folhas de pessoal e previdenciários, sem mencionar as dificuldades de controle e a corrupção política.

No caso em tela, observou-se que os gastos do governo do Piauí têm crescido, embora o governo tenha mantido uma proporção dos gastos referentes a despesas correntes e de capital, girando em torno de $85 \%$ e $15 \%$, respectivamente.

Quando voltamos o olhar para os grupos de natureza de despesa, os maiores dispêndios governamentais estão alocados nos grupos de pessoal e encargos sociais, outras despesas correntes, e com os investimentos. Ainda de acordo com os grupos, mas relacionando-os com as categorias de despesa, os gastos maiores são efetivados com despesas correntes, num total de quase $1 / 3$ dos gastos totais.

Já os gastos com funções, apresentam dados que a literatura tem discutido que são os crescentes gastos com folha de pessoal e dispêndios previdenciários, ligados a fatores institucionais, consequentemente, há detrimento dos gastos com investimentos, razão pela qual os governos estaduais, inclusive o piauiense, carecem de planejamento orçamentário dos gastos, priorizando as despesas obrigatórias, noutras palavras, com boa parte das despesas correntes, finalizando a programação destinando aos investimentos o saldo restante.

\section{REFERÉNCIAS}

BRASIL. Lei no 4.320. Promulgada em 17 de março de 1964. Disponível em: http://www.planalto.gov.br/ccivil_03/leis/L4320.htm. Acesso em: 21 de jun. 2017.

. Constituição Federal de 1988. Promulgada em 5 de outubro de 1988. Disponível em http://www.planalto.gov.br/ccivil_03/constituicao/constituição.htm. Acesso em: 21 jun. 2017.

Portaria no 42. Ministério do Orçamento e Gestão. Brasília, 1999. Disponível em: https://www.legisweb.com.br/legislacao/?id=182092. Acesso em: 21 de jun. 2017.

. Lei Complementar no 101. Promulgada em 04 de maio de 2000. Disponível em: http://www.planalto.gov.br/ccivil_03/leis/LCP/Lcp101.htm. Acesso em: 21 de jun. 2017.

. Manual de Contabilidade Aplicada ao Setor Público. Ministério da Fazenda:

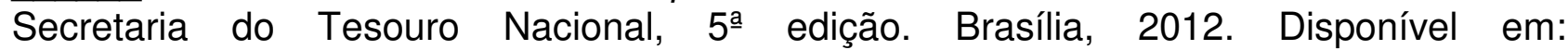


http://www.tesouro.fazenda.gov.br/documents/10180/113505/Parte_VI_PR2012.pdf. Acesso em: 21 de jun. 2017.

DAIN, S. O financiamento público na perspectiva da política social. In: Economia e sociedade, dez. 2001.

HOLANDA, M. C. Gastos com Pessoal em Contexto de Ajuste Fiscal: o caso dos estados do Ceará, Maranhão e Piauí. CERES/FGV, 1997.

REZENDE, Fernando Antônio. Finanças Públicas, 2 edição, SP, Atlas, 2001.

ROCHA, A.C. O processo orçamentário brasileiro como instrumento de accountability, EnAPG, Salvador, nov. 2008.

SANCHES, A. Algumas reflexões sobre o processo orçamentário no Brasil. Texto acessado no google acadêmico em março de 2017.

SANTOS, R. S. A teoria das finanças públicas no contexto do capitalismo: Uma discussão com os filósofos economistas de Smith a Keynes. Mandacaru -Cetead, 2001.

SISTEMA DE INFORMAÇÕES CONTÁBEIS E FISCAIS DO SETOR PÚBLICO BRASILEIRO (Siconfi). Disponível em: https://siconfi.tesouro.gov.br/siconfi/pages/public/consulta_finbra/finbra_list.jsf. Acesso em: 19 de jun. de 2017. 